\title{
BMJ Open Multicentre point-prevalence survey of antibiotic use and healthcare-associated infections in Ethiopian hospitals
}

\author{
Atalay Mulu Fentie (1D , ${ }^{1}$ Yidnekachew Degefaw, ${ }^{2}$ Getachew Asfaw, ${ }^{2}$ \\ Wendosen Shewarega, ${ }^{2}$ Mengistab Woldearegay, ${ }^{3}$ Ephrem Abebe (D) ,,5 \\ Gebremedhin Beedemariam Gebretekle $e^{6,7}$
}

To cite: Fentie AM, Degefaw Y, Asfaw G, et al. Multicentre point-prevalence survey of antibiotic use and healthcareassociated infections in Ethiopian hospitals. BMJ Open 2022;12:e054541. doi:10.1136/ bmjopen-2021-054541

- Prepublication history and additional supplemental material for this paper are available online. To view these files, please visit the journal online (http://dx.doi.org/10.1136/ bmjopen-2021-054541).

EA and $G B G$ are joint senior authors.

Received 15 June 2021 Accepted 31 January 2022

Check for updates

(C) Author(s) (or their employer(s)) 2022. Re-use permitted under CC BY-NC. No commercial re-use. See rights and permissions. Published by BMJ.

For numbered affiliations see end of article.

Correspondence to Atalay Mulu Fentie; atalay.mulu@aau.edu.et

\section{ABSTRACT}

Objective Effective antimicrobial containment strategies such as Antimicrobial Stewardship Programs (ASPs) require comprehensive data on antibiotics use which are scarce in Ethiopia. This study sought to assess antibiotics use and healthcare-associated infections (HCAls) in Ethiopian public hospitals.

Design We conducted a cross-sectional study using the WHO point-prevalence survey protocol for systemic antibiotics use and HCAls for low/middle-income countries.

Setting The study was conducted among 10 public hospitals in 2021.

Participants All patients admitted to adult and paediatric inpatient and emergency wards before or at 08:00 on the survey date were enrolled.

Outcome measure The primary outcome measures were the prevalence of antibiotic use, HCAls and the hospitals' readiness to implement ASP.

Results Data were collected from 1820 patient records. None of the surveyed hospitals had functional ASP. The common indication for antibiotics was for HCAls (40.3\%). Pneumonia was the most common bacterial infection (28.6\%) followed by clinical sepsis (17.8\%). Most treatments were empiric (96.7\%) and the overall prevalence of antibiotic use was $63.8 \%$ with antibiotics prescription per patient ratio of 1.77 . Ceftriaxone was the most commonly prescribed antibiotic (30.4\%) followed by metronidazole (15.4\%). Age, having HIV infection, ward type, type of hospital, catheterisation and intubation history had significant association with antibiotic use. Patients who were treated in paediatric surgical wards were about four times more likely to be on antibiotics compared with patients treated at an adult emergency ward. Patients on urinary catheter (adjusted OR $(\mathrm{AOR})=2.74,95 \% \mathrm{Cl}: 2.04$ to 3.68) and intubation device (AOR=2.62, 95\% Cl: 1.02 to $6.76)$ were more likely to be on antibiotics than their nonintubated/non-catheterised counterparts. Patients treated at secondary-level hospitals had 0.34 times lower odds of being on antibiotics compared with those in tertiary hospitals.

Conclusions Antibiotic use across the surveyed hospitals was common and most were empiric which has both practical and policy implications for strengthening ASP and promoting rational antibiotics use.
Strengths and limitations of this study

- The study enrolled large sample size and was conducted across institutions from diverse geographic regions yielding robust findings.

- The study used a standardized and validated World Health Organization's point prevalence survey tool developed for low- and middle-income countries.

- The findings may have limited generalisability given the study's focus on selected secondary and tertiary public hospitals of Ethiopia.

- Surgical prophylaxis may have been switched to empiric treatment without documentation, potentially inflating rate of prolonged prophylactic antibiotic use and underestimating rate of healthcare-associated infection.

\section{INTRODUCTION}

Since their discovery, antimicrobials have saved millions of lives, substantially reduced disease burden, improved patients' quality of life and helped increase life expectancy. ${ }^{1}$ However, antimicrobial resistance (AMR) is becoming a growing threat to the health of humans, animals and the environment. ${ }^{2}$ Every year, more than 700000 deaths are attributable to AMR and, unless urgent measures are taken, AMR will lead to 10 million deaths and would cost the global economy up to US\$ 100 trillion by 2050 . It is also predicted that AMR will disproportionately affect low/ middle-income countries (LMICs). ${ }^{3}$ Hence, containing and controlling AMR demands multisectoral collaboration and coordinated efforts across diverse sectors. ${ }^{4}$

Although AMR is a complex problem with many inter-related contributors, the key drivers to the emergence of AMR are misuse and overuse of antimicrobials. ${ }^{5}{ }^{6}$ There is a strong correlation between antibiotic consumption and the emergence of resistant microbes. ${ }^{7-10}$ To address this issue, the WHO has developed a Global Action Plan (GAP), ${ }^{6}$ 
which includes a standardised point-prevalence survey (PPS) methodology to guide optimisation of antimicrobial use and AMR containment. ${ }^{11}$

Prior studies from Ethiopia have shown widespread misuse and overuse of antibiotics ${ }^{12-14}$ as well as emergence of microbes that are resistant against locally available antibiotics including carbapenems. ${ }^{15} 16$ Responding to this global health priority, the government of Ethiopia adopted the GAP and implemented strategies, including Antimicrobial Stewardship Program (ASP), to prevent and contain AMR. However, a general picture of antibiotic use, prevalence of healthcare-associated infections (HCAIs) and quality of prescribing at a national level is lacking. ${ }^{11}$ Hence, this multicentre PPS survey aimed to collect baseline information about antibiotic use, prevalence of HCAIs, distribution of these infections according to infection site and pathogen and quality of antibiotic prescribing among selected public hospitals in Ethiopia.

\section{METHODS}

\section{Study design and setting}

A multicentre cross-sectional study was conducted in Ethiopian public hospitals in January 2021. We adopted the WHO methodology for PPS of HCAIs and systemic antibiotic use for LMICs V.1.1. ${ }^{11}$ Ethiopia has a three-tier public healthcare system that broadly classifies its facilities as primary, secondary and tertiary level service providers. At the time of this survey, the estimated number of hospitals in Ethiopia was about 464 at any level (378 public, 86 private) of which 25 were tertiary, 58 secondary and 381 primary hospitals. As part of its strategic initiatives, the Ethiopian Ministry of Health identified selected secondary and tertiary public hospitals to serve as the first cohort of facilities that will implement new ASP or strengthen existing programmes. In alignment with the Ministry's programmatic priorities, we have included five secondary and five tertiary care level hospitals. The hospitals were selected based on their readiness to implement the ASP, location and catchment area of service (online supplemental file).

\section{Eligibility criteria}

The inclusion criteria were first applied to the wards in 10 purposively selected hospitals, then to patients in the selected wards, and finally to the antibiotics prescribed and dispensed to those patients as per the WHO PPS methodology for LMICs V.1.1. ${ }^{11}$ We included all hospitalised patients with a complete medical record admitted in the following acute care wards before or at 08:00 on the day of the survey regardless of antibiotic treatment status: adult and paediatric medical, emergency, gynaecology/obstetrics, surgery, intensive care unit (ICU) and oncology-haematology. Excluded patients included: those seen in outpatient departments, outpatient dialysis centres, patients who were discharged before 08:00 of the day of survey but remaining in wards while awaiting transportation, undergoing treatment or surgery and were discharged or expected to be discharged on the same day, and patients receiving outpatient parenteral antibiotic therapy.

We included only oral and parenteral antibiotics when the patient was on active antibiotic therapy at 08:00 on the day of the survey. For instance, if a patient was on treatment with antibiotic-A at 08:00 on the day of the survey but the treatment was changed to antibiotic-B at 10:00, then only antibiotic-A was reported.

\section{Outcome variables}

The outcome variables were prevalence of antibiotic use and HCAIs among hospitalised patients and existence of functional ASP. We considered functional ASP when hospitals had been providing either prospective audit and feedback or preauthorisation and/or formulary restriction. The independent variables were types of the hospital and ward, patients' sociodemographics, clinicalrelated and treatment-related characteristics.

\section{Sample size determination and sampling technique}

For hospitals with $<500$ bed capacity, all eligible participants were surveyed. For those with 500-800 bed capacity, every other patient was surveyed following an alphabetical listing of all eligible inpatients on the day of data collection. The next available record was included if a selected patient or medical record was not available. A consistent approach was employed across wards to ensure fidelity to predefined study procedures. Altogether, 2209 eligible patients were admitted during the survey period, and a total of 1820 patients were included in the survey and final data analyses. As per the WHO PPS methodology, 389 patients were excluded from the survey because they were either (1) undergoing treatment or surgery and were discharged or expected to be discharged on the same day, or (2) admitted to the ward after 08:00 or discharged before 08:00 of the survey date (figure 1).

\section{Data collection and management}

A total of 100 patients, 10 from each of the participating hospitals, were used to pilot test the survey instrument.

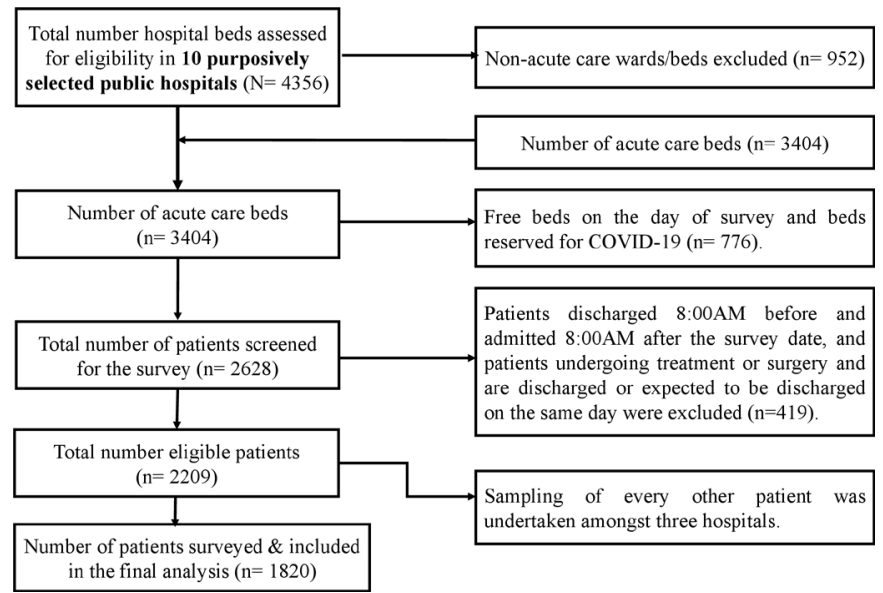

Figure 1 Diagrammatic scheme of study participant recruitment process. 
Trained data collectors fielded the survey instrument (one ASP chair/secretary and two clinical pharmacists per hospital). Data quality was assured through the implementation of a field manual guiding data collectors, regular supervision and daily checks on data completeness, accuracy and clarity. A validation workshop was also conducted to review findings with infectious disease specialists, data collectors and other key stakeholders from the surveyed hospitals and the Ethiopian Ministry of Health.

\section{Patient and public involvement}

The survey was designed for public health surveillance purposes; it was non-experimental, did not involve any patient examination nor did it introduce interventions. There was no direct patient and public involvement in the design, recruitment and conduct of the study. Collected data were de-identified during data collection and it can therefore be considered to be a minimal risk study. All the data were extracted from the respective patient's medical records. Procedures for data collection, data management, analysis and interpretation were in accordance with the ethical and data safety regulations of the country.

\section{Data analysis and interpretation}

Data were analysed using SPSS V.26. Descriptive analyses such as frequency and percentage were used to summarise the data. A multivariable logistic regression analysis was used to explore factors affecting antimicrobial use. During univariate analysis, all variables with $\mathrm{p}<0.25$ and other clinically significant variables (eg, length of hospital stay and within 90 days hospitalisation history) were included for multivariable logistic regression model. A $p$ value of $<0.05$ was considered statistically significant.

\section{RESULTS}

\section{Demographic characteristics of patients}

The mean age of patients was $27.7 \pm 22.1$ years and the majority $(690,37.9 \%)$ of patients were in the age group of 18-39 years. There were about 90 preterm babies. Out of the 1820 patients included in the survey, a large proportion of them were from adult medical $(340,18.7 \%)$, adult surgical $(330,18.1 \%)$ and obstetrics/gynaecology (309, $17.0 \%)$ wards. Five hundred and one $(27.5 \%)$ patients were found to be transferred from other hospitals and $562(30.9 \%)$ had a previous history of hospitalisation in the last 90 days. Moreover, $194(10.7 \%)$ of the patients had HIV infection, $76(4.2 \%)$ had active tuberculosis and $277(15.2 \%)$ of patients were malnourished. A peripheral vascular catheter was secured in a significant number of patients $(1535,84.3 \%)$ (table 1$)$.

\section{Indications for antibiotics}

From the 1820 enrolled patients, there were about 1191 $(65.4 \%)$ antibiotic indications on the day of survey. The most common indication for antibiotics was HCAI (480, $40.3 \%)$. Eight hundred and eighty-seven patients had a
Table 1 Characteristics of patients

\begin{tabular}{|lc|}
\hline Variable, $\mathbf{n = 1 8 2 0}$ & $\mathbf{n}(\%)$ \\
\hline Sex & \\
\hline Male & $848(46.6)$ \\
\hline Female & $972(53.4)$ \\
\hline Age in years & \\
\hline $0-17$ & $616(33.8)$ \\
\hline $18-39$ & $690(37.9)$ \\
\hline $40-64$ & $371(20.4)$ \\
\hline 265 & $143(7.9)$ \\
\hline Type of preterm for pre-term babies, $\mathrm{n}=90$ \\
$\quad$ Late preterm & $39(43.3)$ \\
\hline Moderate preterm & $26(28.9)$ \\
\hline Very preterm & $24(26.7)$ \\
\hline Extremely preterm & $1(0.1)$ \\
\hline
\end{tabular}

Ward/unit type

Adult medical ward

$340(18.7)$

Adult surgical ward

$330(18.1)$

Obstetrics/gynaecology ward

$309(17.0)$

Neonatal intensive care unit

$184(10.1)$

Adult emergency ward

$181(9.9)$

Paediatric medical ward

$146(8.0)$

Paediatric emergency ward

120 (6.6)

Adult intensive care unit $57(3.1)$

Paediatric surgical ward

56 (3.1)

Paediatric high risk wards

42 (2.3)

Adult high risk wards 42 (2.3)

Paediatric intensive care unit $13(0.7)$

Current hospitalisation malarial status

Yes $33(1.8)$

No

1439 (79.1)

Unknown

348 (19.1)

Previous malarial treatment history

$\begin{array}{lr}\text { Yes } & 41(2.3) \\ \text { No } & 1517(83.3) \\ \text { Unknown } & 262(14.4) \\ \text { Active tuberculosis } & \\ \text { Yes } & 76(4.2) \\ \text { No } & 1499(82.4) \\ \text { Unknown } & 245(13.4) \\ \text { IIV infection status } & 194(10.7) \\ \text { Positive } & 1421(78.0) \\ \text { Negative } & 205(11.3) \\ \text { Unknown } & 28(1.5) \\ \text { Patients having chronic obstructive } & \end{array}$

Patients with malnutrition

277 (15.2) 


\begin{tabular}{lc}
\hline Table 1 Continued & \\
\hline Variable, $\mathbf{n}=1820$ & $501(27.5)$ \\
\hline $\begin{array}{l}\text { Referred from another hospital } \\
\text { Patients having hospitalisation history }\end{array}$ & $562(30.9)$ \\
within 90 days & $1535(84.3)$ \\
$\begin{array}{l}\text { Patients with peripheral vascular catheter } \\
\text { at 08:00 on the day of the survey }\end{array}$ & $403(22.1)$ \\
$\begin{array}{l}\text { Patients with urinary catheter at 08:00 on } \\
\text { the day of the survey }\end{array}$ & $71(3.9)$ \\
$\begin{array}{l}\text { Patients that were intubated at 08:00 on } \\
\text { the day of the survey }\end{array}$
\end{tabular}

documented infection, the most common being pneumonia $(254,28.6 \%)$ followed by clinical sepsis (158, $17.8 \%$ ) and central nervous system infections (118, $13.3 \%$ ) (table 2).

Table 2 Indication for antibiotics and types of infections

\begin{tabular}{|c|c|c|}
\hline Variable & & n (\%) \\
\hline \multirow{5}{*}{$\begin{array}{l}\text { Indication of } \\
\text { antibiotics among } \\
1191 \text { indications }\end{array}$} & $\begin{array}{l}\text { Healthcare-associated } \\
\text { infections }\end{array}$ & $480(40.3)$ \\
\hline & $\begin{array}{l}\text { Community-acquired } \\
\text { infection }\end{array}$ & $403(33.8)$ \\
\hline & Surgical prophylaxis & $218(18.3)$ \\
\hline & Medical prophylaxis & $86(7.2)$ \\
\hline & Unknown & $4(0.3)$ \\
\hline \multirow{11}{*}{$\begin{array}{l}\text { Types of infection } \\
\text { among the } \\
887 \text { patients }\end{array}$} & Pneumonia & $254(28.6)$ \\
\hline & Clinical sepsis & $158(17.8)$ \\
\hline & $\begin{array}{l}\text { Central nervous system } \\
\text { infection }\end{array}$ & $118(13.3)$ \\
\hline & $\begin{array}{l}\text { Cellulitis, wound, deep soft } \\
\text { tissue infection; not related } \\
\text { to surgery }\end{array}$ & $61(6.9)$ \\
\hline & $\begin{array}{l}\text { Symptomatic upper urinary } \\
\text { tract infection }\end{array}$ & $59(6.7)$ \\
\hline & Gastrointestinal infection & $43(4.8)$ \\
\hline & $\begin{array}{l}\text { Surgical site infection } \\
\text { involving skin or soft tissue } \\
\text { but not bone }\end{array}$ & $39(4.4)$ \\
\hline & Intra-abdominal infection & $35(3.9)$ \\
\hline & Gynaecological infection & $30(3.4)$ \\
\hline & Cardiovascular infection & $19(2.1)$ \\
\hline & Others* & $71(8.0)$ \\
\hline
\end{tabular}

${ }^{*}$ Others: Febrile neutropenia, sexually transmitted infection, infection of ear, nose and throat, cystic fibrosis, symptomatic lower urinary tract infection, acute bronchitis and exacerbation of asthma, septic arthritis of surgical site, prostatitis, systemic inflammatory response with no clear anatomical site, completely undefined site.

\section{Microbiological tests}

Microbiological diagnostics for patients treated for HCAIs and community-acquired infections were rarely ordered during the survey period $(119,13.6 \%)$. If ordered, most of them were blood samples alone $(53,44.5 \%)$, followed by urine culture $(26,21.9 \%)$. Moreover, a high proportion of the results were unknown or not reported/collected $(52,43.7 \%)$. Out of 41 isolated microorganisms, about two-thirds $(28,68.3 \%)$ were gram-negative bacteria. Escherichia coli $(8,19.5 \%)$ and Klebsiella pneumoniae $(7,17.1 \%)$ were the most commonly isolated microbes. About 21 resistant phenotypes were reported and most $(13,61.9 \%)$ were third-generation cephalosporin resistant Enterobacteriaceae followed by methicillin resistant Staphylococcus aureus $(3,14.3 \%)$ and carbapenem resistant Enterobacteriaceae $(3,14.3 \%)$ (table 3$)$.

\section{Readiness to implement ASP}

All surveyed hospitals had functional infection prevention and control committee and only eight hospitals had functional Drugs and Therapeutics Committee. Although a defined organisational structure for ASP was present in all surveyed hospitals, a formal ASP team was only available in seven $(70 \%)$ hospitals and none were functional during the survey period. None of the hospitals monitored antibiotic use per defined daily dose or days of therapy and hospital activity denominator. Microbiological services were available in eight of the surveyed hospitals, and the median number of blood cultures performed in the previous fiscal year 2019/2020 was 1707 (IQR: 680-2786). Different classes of broad-spectrum and narrow-spectrum antibiotics were stocked out during the survey period (online supplemental file).

\section{Antibiotics use prevalence and indication}

Of the 1820 surveyed patients, $63.8 \%$ had at least one antibiotic prescription on the day of the survey. The prevalence of antibiotic use was higher in adult ICU patients $(49,86.0 \%)$ followed by paediatric emergency $(112,76.7 \%)$ and paediatric medical wards $(94,78.3 \%)$ (table 4).

On the day of the survey, 2059 antibiotics were prescribed for 1162 patients with antibiotics prescribing ratio of 1.77 per patient. More than half $(585,50.3 \%)$ patients were on two antibiotics. Most antibiotics were prescribed in their generic name $(1998,97.1 \%)$ and were administered parenterally $(1858,90.2 \%)$. The median duration of treatment from initiation to survey date was 5 days (IQR: 3-10 days). A significantly higher proportion of treatments were empiric $(837,96.7 \%)$. As per the WHO definition of guideline compliance, ${ }^{11}$ only $637(54.8 \%)$ of the treatments were compliant with the national guideline (online supplemental file).

As shown in table 4 , the most widely prescribed antibiotics across all surveyed hospitals were ceftriaxone (626, $30.4 \%$ ) followed by metronidazole $(317,15.4 \%)$, ampicillin $(249,12.1 \%)$ and vancomycin $(217,10.5 \%)$. Additionally, ceftriaxone $(157,54.7 \%)$ was the most widely 
Table 3 Microbiological diagnostics and culture and sensitivity results

\begin{tabular}{|c|c|}
\hline Variable & n (\%) \\
\hline \multicolumn{2}{|l|}{$\begin{array}{l}\text { Sample collected for microbiological workup, } \\
n=870 \text { patients }\end{array}$} \\
\hline Yes & 119 (13.6) \\
\hline No & $693(79.7)$ \\
\hline Unknown & $58(6.7)$ \\
\hline \multicolumn{2}{|l|}{ Specimen type, $n=119$ patients } \\
\hline Blood & $53(44.5)$ \\
\hline Urine & $26(21.9)$ \\
\hline Cerebrospinal fluid & $13(10.9)$ \\
\hline Pus & $11(9.2)$ \\
\hline Blood and urine & $8(6.7)$ \\
\hline Blood and cerebrospinal fluid & $6(5.1)$ \\
\hline Peritoneal fluid & $2(1.7)$ \\
\hline \multicolumn{2}{|l|}{ Culture result, $n=119$ patients } \\
\hline Positive & $38(31.9)$ \\
\hline Negative & $29(24.4)$ \\
\hline Unknown & $52(43.7)$ \\
\hline \multicolumn{2}{|l|}{ Isolated microorganism, $\mathrm{n}=41$} \\
\hline Gram positive bacteria & $13(31.7)$ \\
\hline Gram negative bacteria & $28(68.3)$ \\
\hline \multicolumn{2}{|l|}{ Type of isolated bacteria, $n=41 \dagger$} \\
\hline Escherichia coli & $8(19.5)$ \\
\hline Klebsiella pneumoniae & $7(17.1)$ \\
\hline Klebsiella oxytoca & $4(9.8)$ \\
\hline Acinetobacter & $4(9.8)$ \\
\hline Staphylococcus aureus & $4(9.8)$ \\
\hline Enterobacter aerogenes & $3(7.3)$ \\
\hline Enterococcus & $3(7.3)$ \\
\hline $\begin{array}{l}\text { Coagulase negative staphylococcus, } \\
\text { contaminant }\end{array}$ & $3(7.3)$ \\
\hline Others $\ddagger$ & $5(12.2)$ \\
\hline \multicolumn{2}{|l|}{ Resistant phenotype, $n=21$} \\
\hline $\begin{array}{l}\text { Third-generation cephalosporin resistant } \\
\text { Enterobacteriaceae }\end{array}$ & $13(61.9)$ \\
\hline Methicillin resistant Staphylococcus aureus & $3(14.3)$ \\
\hline Carbapenem resistant Enterobacteriaceae & $3(14.3)$ \\
\hline $\begin{array}{l}\text { Carbapenem resistant } P \text { seudomonas } \\
\text { aeruginosa }\end{array}$ & $1(4.8)$ \\
\hline Carbapenem resistant Acinetobacter & $1(4.8)$ \\
\hline
\end{tabular}

*Only for those whose indication type is for healthcare-associated infection and community-acquired infection.

†For one patient Klebsiella oxytoca from blood and Klebsiella pneumoniae from urine, from another patient streptococcus from blood and Klebsiella pneumoniae from blood and another one Klebsiella pneumoniae from urine and Acinetobacter from blood were isolated.

$\ddagger$ Pseudomonas aeruginosa, Citrobacter, Gram positive cocci, Group A streptococcus, Group D streptococcus. prescribed antibiotic for surgical prophylaxis followed by metronidazole $(64,22.3 \%)$. A significantly higher proportion of patients $(180,82.6 \%)$ were on prolonged duration of antibiotics for surgical prophylaxis (defined as $>24$ hours use).

\section{Factors associated with antibiotic use}

From the multivariable logistic regression analysis, age, ward type, hospital type, history of being catheterised, history of being intubated and HIV infection status were significantly associated with being on antibiotics. Patients aged between 18-39years (adjusted OR $(\mathrm{AOR})=0.61$, 95\% CI: 0.38 to 0.86 ) and $40-64$ years old (AOR $=0.55$, 95\% CI: 0.39 to 0.93 ) had lower odds of being on antibiotics compared with 17 years old or younger patients. Moreover, patients treated in paediatric medical and emergency wards were about four times more likely to be on antibiotics compared with patients in an adult emergency ward. The study also found that being on urinary catheter and intubation device had a significant association with antibiotics use status, where they were nearly three times more likely to be on antibiotics compared with non-catheterised and non-intubated counterparts (table 5).

\section{DISCUSSION}

AMR is becoming a global threat exacting a major toll on human, animal and environmental health. ${ }^{17-20}$ Ethiopia, like many nations, has not been immune from the negative effects of AMR. ${ }^{162122}$ While there have been initiatives to address this pressing health challenge, the few national and institutional efforts have had limited success. Mounting an effective national response to combat AMR requires robust information on the scope of infections and antimicrobial agents being used in healthcare institutions. Using the WHO's standardised PPS methodology, this study assessed the burden of HCAIs and antibiotic use in selected public hospitals of Ethiopia.

Similar to studies done elsewhere, ${ }^{132324}$ the most common indication for antibiotics therapy was for HCAIs (40.3\%), with pneumonia and clinical sepsis accounting for the lion share of indications. This high burden of infections might be a reason for misuse and overuse of antibiotics, potentially straining the already resource constrained hospitals, patients and family caregivers. ${ }^{13}$ Hence, efforts to effectively treat, prevent and reduce HCAIs are needed. To achieve these, implementing interventions such as strengthening and integrating infection prevention and control practice, developing and enforcing the use of institution specific standard treatment guidelines and providing in-service trainings are needed. Strengthening microbiology laboratories to guide definitive treatment is also invaluable towards the achievement of this goal.

Empiric prescribing for broad-spectrum antibiotics (96.7\%) was a common finding across the surveyed hospitals, something that has been reported in studies from 
Table 4 Proportion of patients on antibiotics and types of antibiotics prescriptions

\begin{tabular}{|c|c|}
\hline Antibiotics & n (\%) \\
\hline \multicolumn{2}{|c|}{$\begin{array}{l}\text { Proportion of patients on antibiotics per surveyed wards, } \\
\mathrm{n}=1162\end{array}$} \\
\hline Adult surgical ward & $219(66.4)$ \\
\hline Adult medical ward & $199(58.5)$ \\
\hline Obstetrics and gynaecology & $157(50.8)$ \\
\hline Neonatal intensive care unit & $140(76.1)$ \\
\hline Paediatric medical ward & $112(76.7)$ \\
\hline Adult emergency ward & $97(53.6)$ \\
\hline Paediatric emergency ward & $94(78.3)$ \\
\hline Adult intensive care unit & $49(86)$ \\
\hline Paediatric surgical ward & $41(73.2)$ \\
\hline Paediatric high risk wards & $32(76.2)$ \\
\hline Adult high risk ward & $13(31)$ \\
\hline Paediatric intensive care unit & $9(69.2)$ \\
\hline \multicolumn{2}{|c|}{ Types of antibiotics prescribed for therapeutic use, n=2059 } \\
\hline Ceftriaxone & $626(30.4)$ \\
\hline Metronidazole & $317(15.4)$ \\
\hline Ampicillin & $249(12.1)$ \\
\hline Vancomycin & $217(10.5)$ \\
\hline Gentamycin & $178(8.6)$ \\
\hline Ceftazidime & $116(5.6)$ \\
\hline Trimethoprim/sulphamethoxazole & $72(3.5)$ \\
\hline Cloxacillin & $49(2.4)$ \\
\hline Ciprofloxacin & $42(2.0)$ \\
\hline Cefepime & $40(1.9)$ \\
\hline Meropenam & $39(1.9)$ \\
\hline Azithromycin & $25(1.2)$ \\
\hline Others* $^{*}$ & $89(4.3)$ \\
\hline \multicolumn{2}{|c|}{ Type of antibiotics prescribed for surgical prophylaxis, $n=287$} \\
\hline Ceftriaxone & $157(54.7)$ \\
\hline Metronidazole & $64(22.3)$ \\
\hline Ampicillin & $55(19.2)$ \\
\hline Cephalexin & $4(1.4)$ \\
\hline Amoxicillin & $3(1.0)$ \\
\hline Others† & $4(1.4)$ \\
\hline \multicolumn{2}{|c|}{ Dosage for surgical prophylaxis, $n=218$ patients } \\
\hline Single dose & $7(3.2)$ \\
\hline Multiple doses over 24 hours only & $31(14.2)$ \\
\hline Multiple doses for more than 24 hours & $180(82.6)$ \\
\hline
\end{tabular}

Ratio of antibiotics per surgical procedure (number of antibiotics used for surgery/total number of patients who were on SP) $=1.32$

*Amoxacillin=20; Cefotaxime=13; Amoxacillin-clavulanic acid=12; Cephalexin=9; Crystalline-penicillin=6; Erythromycin=6; Norfloxacin=5; Benzanthine penicillin=4; Clindamycin=4; Doxycycline=3; Chloramphenicol=2; Clarithromycin=1; Nitrofurantoin=1; Cefixime=1; Ampicillin-sulbactam $=1$. †Amoxicillin-clavulanate, Ciprofloxacin, Cloxacillin and Gentamycin.

‡SP: Surgical prophylaxis 
Table 5 Univariate and multi-variable binary logistic regression analysis of predictors of antibiotics use among the surveyed hospitals

\begin{tabular}{|c|c|c|c|c|}
\hline \multirow[b]{2}{*}{ Variables } & \multicolumn{2}{|c|}{ Patient on antibiotics } & \multirow[b]{2}{*}{ COR, $95 \% \mathbf{C l}$} & \multirow[b]{2}{*}{ AOR, 95\% Cl } \\
\hline & Yes, n (\%) & No, n (\%) & & \\
\hline \multicolumn{5}{|l|}{ Age in years } \\
\hline $0-17$ & $460(39.6)$ & $156(23.7)$ & 1.00 & 1.00 \\
\hline $18-39$ & $406(34.9)$ & $284(43.6)$ & $0.49(0.38 \text { to } 0.61)^{\star *}$ & $0.61(0.38 \text { to } 0.86)^{\star}$ \\
\hline $40-64$ & $211(18.2)$ & $160(24.3)$ & $0.45(0.34 \text { to } 0.59)^{\star}$ & $0.55(0.39 \text { to } 0.93)^{\star}$ \\
\hline$\geq 65$ & $85(7.3)$ & $58(8.8)$ & $0.5(0.34 \text { to } 0.73)^{\star \star}$ & 1.45 (0.31 to 3.59$)$ \\
\hline \multicolumn{5}{|l|}{ Gender } \\
\hline Female & $584(50.3)$ & $388(59.0)$ & 1.00 & 1.00 \\
\hline Male & $578(49.7)$ & $270(41.0)$ & $1.42(1.17 \text { to } 1.73)^{*}$ & 1.18 (0.93 to 1.49$)$ \\
\hline \multicolumn{5}{|l|}{ Ward type } \\
\hline Paediatric medical & $112(9.6)$ & $34(5.2)$ & $2.85(1.76 \text { to } 4.62)^{\star}$ & $3.78(1.81 \text { to } 7.9)^{\star \star}$ \\
\hline Paediatric surgical & $41(3.5)$ & $15(2.3)$ & 2.37 (1.22 to 4.58$)$ & 2.31 (0.96 to 5.51$)$ \\
\hline Paediatric high risk & $32(27.5)$ & $10(1.5)$ & 2.77 (1.29 to 5.97$)$ & $4.15(1.59 \text { to } 10.8)^{*}$ \\
\hline Paediatric ICU & $9(0.8)$ & $4(0.6)$ & 1.95 (0.58 to 6.56$)$ & 1.57 (0.38 to 6.50$)$ \\
\hline Paediatric emergency & $94(8.1)$ & $26(4.0)$ & $3.13(1.86 \text { to } 5.28)^{\star}$ & $4.22(1.98 \text { to } 9.02)^{\star \star}$ \\
\hline Neonatal ICU & $140(12.0)$ & $44(6.7)$ & $2.76(1.76 \text { to } 4.31)^{\star}$ & $3.27(1.59 \text { to } 6.67)^{*}$ \\
\hline Adult medical & $199(17.1)$ & $141(21.4)$ & 1.22 (0.85 to 1.76$)$ & 1.31 (0.89 to 1.92$)$ \\
\hline Adult surgical & $219(18.8)$ & $111(16.9)$ & 1.71 (1.18 to 2.48$)$ & $2.00(1.36 \text { to } 2.95)^{\star \star}$ \\
\hline Adult high risk & $13(1.1)$ & $29(4.4)$ & 0.39 (0.19 to 0.79$)$ & $0.45(0.22 \text { to } 0.96)^{*}$ \\
\hline Adult ICU & $49(4.2)$ & $8(1.2)$ & $5.30(2.38 \text { to } 11.83)^{\star}$ & 2.68 (1.05 to 6.88$)$ \\
\hline Gynaecology/obstetrics & $157(13.5)$ & $152(23.1)$ & 0.89 (0.62 to 1.29$)$ & $0.83(0.54$ to 1.27$)$ \\
\hline Adult emergency & $97(8.3)$ & $84(12.8)$ & 1.00 & 1.00 \\
\hline \multicolumn{5}{|l|}{ Urinary catheterisation status } \\
\hline No & $846(72.8)$ & $571(86.8)$ & 1.00 & 1.00 \\
\hline Yes & $316(27.2)$ & $87(13.2)$ & $2.45(1.89 \text { to } 3.18)^{\star}$ & $2.74(2.04 \text { to } 3.68)^{\star}$ \\
\hline \multicolumn{5}{|l|}{ Intubation status } \\
\hline No & $1098(94.5)$ & $650(98.8)$ & 1.00 & 1.00 \\
\hline Yes & $63(5.5)$ & $8(1.2)$ & $4.66(2.22 \text { to } 9.79)^{\star}$ & $2.62(1.02 \text { to } 6.76)^{\star \star}$ \\
\hline \multicolumn{5}{|l|}{ HIV infection status } \\
\hline Yes & $161(13.9)$ & $33(5.0)$ & 1.00 & 1.00 \\
\hline No & $867(74.6)$ & $554(84.2)$ & $0.32(0.22 \text { to } 0.47)^{\star \star}$ & $0.19(0.13 \text { to } 0.30)^{\star *}$ \\
\hline Unknown & $134(11.5)$ & $71(10.8)$ & $0.39(0.24 \text { to } 0.62)^{\star \star}$ & $0.24(0.15 \text { to } 0.40)^{\star *}$ \\
\hline \multicolumn{5}{|c|}{ Within 90 days hospitalisation history } \\
\hline Yes & $366(31.5)$ & $196(29.8)$ & 1.00 & 1.00 \\
\hline No & $796(68.5)$ & $462(70.2)$ & 0.93 (0.75 to 1.14$)$ & 0.85 (0.67 to 1.06$)$ \\
\hline Length of hospitalisation in days & & & 0.998 (0.99 to 1.00$)$ & 1.00 (0.99 to 1.01$)$ \\
\hline \multicolumn{5}{|l|}{ Hospital type } \\
\hline Secondary care & $623(53.6)$ & $304(46.2)$ & 1.00 & 1.00 \\
\hline Tertiary care & $539(46.4)$ & $354(53.8)$ & $0.74(0.61 \text { to } 0.90)^{\star}$ & $0.66(0.53 \text { to } 0.81)^{\star}$ \\
\hline
\end{tabular}

${ }^{*} \mathrm{p}<0.05,{ }^{*}$ statistically significant at $\mathrm{p}<0.0001$.

AOR, adjusted OR; COR, crude OR; ICU, intensive care unit.

other LMICs. ${ }^{24-27}$ This may have resulted from lack ofand poor utilisation of microbiology services, as seen by the hospitals' limited use of culture and sensitivity tests.
This also parallels the overuse of antibiotics in general $(63.8 \%)$, consistent with findings from countries with similar economic contexts (use ranging from $70.6 \%$ to 
$80.1 \%)^{24-27}$ but contrasting with those from high-income countries (HICs) $(27.1 \%-50.3 \%) .{ }^{23}{ }^{28-30}$ An internetbased PPS done across 53 countries (LMICs and HICs) has also reported higher antimicrobial use in LMICs compared with HICs. ${ }^{31}$

A high prevalence of empiric antibiotics use in many LMICs compared with HICs ${ }^{132631}$ might be attributed to lack of a national and institutional antibiotic guideline and poor diagnostic infrastructure which can promote empiric but also high rates of irrational antibiotic use. Although most of the surveyed hospitals had microbiological services, only one hospital developed institutional guideline as per the antibiogram data. This suggests poor utilisation of microbiology services to guide empiric antibiotic use and highlights the missed opportunities in promoting rational antibiotic use. ${ }^{32}$ Recently, a pharmacist-led ASP implemented in one of the tertiary care hospitals of Ethiopia was well received and shown to be beneficial. ${ }^{13}$ Lessons from such programmes should be leveraged to promote widespread adoption of ASP to decrease antibiotic consumption, save costs and improve outcomes. Additionally, enhancing capacity of existing ASPs through leadership and governance support will be critical as these were identified to be deficient in the surveyed hospitals.

In this study, there was also a substantial difference in the prevalence of antibiotics use across different levels of surveyed hospitals where a statistically significant higher antibiotic use was reported in tertiary care hospitals compared with secondary hospitals. There were also disparities with respect to the type of prescribed antibiotics compared with other studies. Similar to studies done in Pakistan ${ }^{26}$ and Ethiopia, ${ }^{12} 1325$ the most widely prescribed antibiotic was the third-generation cephalosporin, ceftriaxone $(30.4 \%)$ which is included under the WHO watch category of Access, Watch and Reserve (AWaRe) classification of antibiotics. ${ }^{6}$ In developed countries, however, the most commonly prescribed antibiotics were penicillins with $\beta$-lactamase inhibitors. ${ }^{23}{ }^{31}$ Nitroimidazoles were the most commonly prescribed antibiotics in Nigeria. ${ }^{8}$

Prolonged use of surgical prophylaxis ( $>24$ hours) was high in this study $(82.6 \%)$, similar to studies from other LMICs (73\%-100\%). ${ }^{24} 262733-35$ The recommended duration of surgical prophylaxis is 1 day $^{36-38}$ since prolonging duration potentially increases the rate of AMR, side effects and costs for both the patient and the hospital. ${ }^{39-41}$ Furthermore, average number of antibiotics prescribed per patient for surgical prophylaxis was 1.32 despite several studies and guidelines demonstrating the costeffectiveness of single narrow-spectrum antibiotics, usually cefazolin. ${ }^{30}{ }^{36}{ }^{42-45}$ However, in the current study, ceftriaxone $(54.7 \%)$ was the widely prescribed antibiotic for surgical prophylaxis. The widespread use of broadspectrum third-generation cephalosporins in our survey might be due to unavailability of cefazolin in all of the surveyed hospitals. Hence, due to proven safety and efficacy of cefazolin, it is time for Ethiopia to include it on the essential medicine list, ensure its availability and develop guidelines to promote use of cefazolin or other narrow-spectrum antibiotics for surgical prophylaxis.

Our study has some limitations. First, the study only included purposely selected tertiary and secondary hospitals. Hence, the findings may not be generalisable to all settings. Second, because this was a PPS (ie, crosssectional study), patients were not followed-up in time. As a result, it was not possible to measure outcomes that had a temporal element such as AMR, duration of antibiotic use and length of hospital stay. Third, some surgical prophylaxis orders might have been changed to empiric treatment for suspected infection without proper documentation reflecting such change. This would inflate the rate of prolonged surgical prophylaxis, but underestimate the true rate of HCAIs. Fourth, the reported microbiology finding may not be representative of the hospital population as a whole and could overestimate rate of AMR. This is because microbiologic investigations are mostly conducted for patients with severe diseases and those who failed first-line therapy.

Despite these limitations, the study is the first multicentre study in Ethiopia using a standardised PPS methodology from the WHO. The findings are based on large sample size and are robust enough to guide similar studies to be conducted in Ethiopia and other LMICs. Furthermore, the findings could aid policymakers and other concerned bodies in strengthening ASP, optimising antibiotics use and containing and preventing AMR.

\section{CONCLUSIONS}

Similar to studies from other LMICs, there was widespread use of antibiotics and a high burden of HCAIs. Moreover, prolonged use of broad-spectrum antibiotics was a common practice for surgical prophylaxis suggesting an important target for ASP intervention. Almost all treatments were empiric and hospitals should be further stimulated to regularly monitor antibiotic use and set local targets to optimise their use.

\section{Author affiliations}

${ }^{1}$ School of Pharmacy, Department of Pharmacology and Clinical Pharmacy, Addis Ababa University, College of Health Sciences, Addis Ababa, Ethiopia

${ }^{2}$ Pharmaceuticals and Medical Equipment Directorate, Ethiopia Ministry of Health, Addis Ababa, Ethiopia

${ }^{3}$ World Health Organization Ethiopia Office, Addis Ababa, Ethiopia

${ }^{4}$ College of Pharmacy, Purdue University, West Lafayette, Indiana, USA

${ }^{5}$ School of Medicine, Indiana University, Indianapolis, Indiana, USA

${ }^{6}$ Institute of Health Policy Management and Evaluation, University of Toronto,

Toronto, Ontario, Canada

${ }^{7}$ Toronto Health Economics and Technology Assessment (THETA) Collaborative, University Health Network, Toronto, Ontario, Canada

Acknowledgements We express our gratitude for all hospitals for their invaluable assistance during our data collection. We also would like to extend our appreciation to the data collectors assigned from the hospitals as well as to all validation workshop participants for their insightful feedback.

Contributors AMF prepared the draft of the manuscript. YD and MW contributed to funding acquisition. AMF, YD, GA, WS and MW contributed to research planning, conduct and organisation of data collection. AMF, YD, GA, WS, MW, EA and GBG 
contributed to supervision, visualisation, conception, design, acquisition of data, analysis and interpretation of the results. AMF, YD, WS, MW, GA, EA and GBG took part in revising it critically for important intellectual content. All authors gave final approval of the manuscript and agree to be accountable for all aspects of the work.

Funding This multicentre PPS of antibiotic use and HCAls in selected hospitals was commissioned by the Ethiopian Federal Ministry of Health (EFMOH) with the financial and technical assistance of the WHO. EA received support through Grant Numbers, KL2TR002530 (B. Tucker Edmonds, PI), and UL1TR002529 (S. Moe and S. Wiehe, co-PIs) from the National Institutes of Health, National Center for Advancing Translational Sciences, Clinical and Translational Sciences Award.

Competing interests None declared.

Patient consent for publication Not applicable.

Ethics approval Ethical approval was obtained from the Ethiopian Federal Ministry of Health (Approval ID: SOM/21/10/13). Before data collection, permission was sought from respective hospital administration. Collected data were de-identified during data collection and data were analysed in aggregate to maintain confidentiality and anonymity of information.

Provenance and peer review Not commissioned; externally peer reviewed.

Data availability statement All data relevant to the study are included in the article or uploaded as supplementary information. Not applicable.

Supplemental material This content has been supplied by the author(s). It has not been vetted by BMJ Publishing Group Limited (BMJ) and may not have been peer-reviewed. Any opinions or recommendations discussed are solely those of the author(s) and are not endorsed by BMJ. BMJ disclaims all liability and responsibility arising from any reliance placed on the content. Where the content includes any translated material, BMJ does not warrant the accuracy and reliability of the translations (including but not limited to local regulations, clinical guidelines, terminology, drug names and drug dosages), and is not responsible for any error and/or omissions arising from translation and adaptation or otherwise.

Open access This is an open access article distributed in accordance with the Creative Commons Attribution Non Commercial (CC BY-NC 4.0) license, which permits others to distribute, remix, adapt, build upon this work non-commercially, and license their derivative works on different terms, provided the original work is properly cited, appropriate credit is given, any changes made indicated, and the use is non-commercial. See: http://creativecommons.org/licenses/by-nc/4.0/.

\section{ORCID iDs}

Atalay Mulu Fentie http://orcid.org/0000-0001-6065-0695

Ephrem Abebe http://orcid.org/0000-0001-7078-1904

\section{REFERENCES}

1 Kardos N, Demain AL. Penicillin: the medicine with the greatest impact on therapeutic outcomes. Appl Microbiol Biotechnol 2011;92:677-87.

2 Lobanovska M, Pilla G. Penicillin's discovery and antibiotic resistance: lessons for the future? Yale J Biol Med 2017;90:135-45

3 O'Neill J. Antimicrobial Resistance: Tackling a crisis for the health and wealth of nations, 2016. Available: https://wellcomecollection. org/works/rdpck35v

4 The World Bank. Drug-Resistant infections: a threat to our economic future. world bank Rep, 2017. Available: https://openknowledge. worldbank.org/handle/10986/26707

5 Michael CA, Dominey-Howes D, Labbate M. The antimicrobial resistance crisis: causes, consequences, and management. Front Public Health 2014;2:145.

6 World Health Organization. Global action plan on antimicrobial resistance. Microbe Mag 2015;10:354-5.

7 Centers for Disease Control and Prevention. Antibiotic use in the United States. progress and opportunities. Atlanta, GA: US Department of Health and Human Services. CDC, 2017.

8 Abubakar U. Point-Prevalence survey of hospital acquired infections in three acute care hospitals in northern Nigeria. Antimicrob Resist Infect Control 2020;9:1-7.

9 Ayukekbong JA, Ntemgwa M, Atabe AN. The threat of antimicrobial resistance in developing countries: causes and control strategies. Antimicrob Resist Infect Control 2017;6:1-8.

10 Mboya EA, Sanga LA, Ngocho JS. Irrational use of antibiotics in the Moshi Municipality Northern Tanzania: a cross sectional study. Pan Afr Med J 2018;31:1-10.
11 World Health Organization. Who methodology for point prevalence survey on antibiotics use in hospitals, 2018. Available: https://apps. who.int/iris/handle/10665/280063

12 Alemkere G, Tenna A, Engidawork E. Antibiotic use practice and predictors of hospital outcome among patients with systemic bacterial infection: identifying targets for antibiotic and health care resource stewardship. PLoS One 2019;14:e0212661.

13 Gebretekle GB, Haile Mariam D, Abebe Taye W, et al. Half of prescribed antibiotics are not needed: a pharmacist-led antimicrobial stewardship intervention and clinical outcomes in a referral hospital in Ethiopia. Front Public Health 2020;8:109.

14 Argaw NA, Shumbash KZ, Asfaw AA, et al. Assessment of surgical antimicrobial prophylaxis in orthopaedics and Traumatology surgical unit of a tertiary care teaching hospital in Addis Ababa. BMC Res Notes 2017;10:160.

15 Abebe W, Alemayehu T, Kong L. Alarming rates of drug-resistant Gram-negative bloodstream infections among hospitalized patients in Ethiopia : an urgent call to strengthen diagnostic bacteriology and antimicrobia. 28th Eur Congr Clin Microbiol Infect Dis 2018.

16 Alemayehu T, Ali M, Mitiku E. The burden of antimicrobial resistance at tertiary care hospital, southern Ethiopia: a three years retrospective study. BMC Infect Dis 2019;2017:585.

17 Mouiche MMM, Moffo F, Akoachere J-FTK, et al. Antimicrobial resistance from a one health perspective in Cameroon: a systematic review and meta-analysis. BMC Public Health 2019;19:1135.

18 Nellums LB, Thompson $\mathrm{H}$, Holmes A, et al. Antimicrobial resistance among migrants in Europe: a systematic review and meta-analysis. Lancet Infect Dis 2018;18:796-811.

19 Aminov RI. A brief history of the antibiotic era: lessons learned and challenges for the future. Front Microbiol 2010;1:134.

20 Midega J. Estimating the global burden of antimicrobial resistance: reflections on current methods and data needs. Wellcome Open Res 2020;5:48.

21 Muhie OA. Antibiotic use and resistance pattern in Ethiopia: systematic review and meta-analysis. Int J Microbiol 2019;2019:2489063.

22 Ibrahim RA, Teshale AM, Dinku SF, et al. Corrigendum: antimicrobial resistance surveillance in Ethiopia: implementation experiences and lessons learned. Afr J Lab Med 2019;8:1-4.

23 Frenette C, Sperlea D, German GJ, et al. The 2017 global point prevalence survey of antimicrobial consumption and resistance in Canadian hospitals. Antimicrob Resist Infect Control 2020;9:104.

24 Anand Paramadhas BD, Tiroyakgosi C, Mpinda-Joseph P, et al. Point prevalence study of antimicrobial use among hospitals across Botswana; findings and implications. Expert Rev Anti Infect Ther 2019;17:535-46.

25 Gutema G, Håkonsen H, Engidawork E, et al. Multiple challenges of antibiotic use in a large hospital in Ethiopia - a ward-specific study showing high rates of hospital-acquired infections and ineffective prophylaxis. BMC Health Serv Res 2018;18:326.

26 Saleem Z, Saeed H, Hassali MA, et al. Pattern of inappropriate antibiotic use among hospitalized patients in Pakistan: a longitudinal surveillance and implications. Antimicrob Resist Infect Control 2019;8.

27 Abubakar U. Antibiotic use among hospitalized patients in northern Nigeria: a multicenter point-prevalence survey. BMC Infect Dis 2020;20:1-9.

28 Ciofi Degli Atti ML, D'Amore C, Ceradini J, et al. Prevalence of antibiotic use in a tertiary care hospital in Italy, 2008-2016. Ital J Pediatr 2019;45:63.

29 Sorensen H. Trends in U. S. antibiotic use. Pew Charit Trust 2018:1-9.

30 Vandael E, Latour K, Goossens H, et al. Point prevalence survey of antimicrobial use and healthcare-associated infections in Belgian acute care hospitals: results of the Global-PPS and ECDC-PPS 2017 Antimicrob Resist Infect Control 2020;9:1-13.

31 Versporten A, Zarb P, Caniaux I, et al. Antimicrobial consumption and resistance in adult hospital inpatients in 53 countries: results of an Internet-based global point prevalence survey. Lancet Glob Health 2018;6:e619-29.

32 de With K, Allerberger F, Amann S, et al. Strategies to enhance rational use of antibiotics in hospital: a guideline by the German Society for infectious diseases. Infection 2016;44:395-439.

33 Afriyie DK, Sefah IA, Sneddon J, et al. Antimicrobial point prevalence surveys in two Ghanaian hospitals: opportunities for antimicrobial stewardship. JAC Antimicrob Resist 2020;2:1-9.

34 Horumpende PG, Mshana SE, Mouw EF, et al. Point prevalence survey of antimicrobial use in three hospitals in north-eastern Tanzania. Antimicrob Resist Infect Control 2020;9:149.

35 van der Sandt N, Schellack N, Mabope LA, et al. Surgical antimicrobial prophylaxis among pediatric patients in South 
Africa comparing two healthcare settings. Pediatr Infect Dis $J$ 2019;38:122-6.

36 Berríos-Torres SI, Umscheid CA, Bratzler DW, et al. Centers for disease control and prevention guideline for the prevention of surgical site infection, 2017. JAMA Surg 2017;152:784-791.

37 Bratzler DW, Dellinger EP, Olsen KM, et al. Clinical practice guidelines for antimicrobial prophylaxis in surgery. Surg Infect 2013;14:73-156.

38 Jocum J. Surgical antibiotic prophylaxis: are you doing it right? South African J Anaesth Analg 2018;24:S49-53.

39 Roberts SA, Morris AJ. Surgical antibiotic prophylaxis: more is not better. Lancet Infect Dis 2020;20:1110-1.

40 Bratzler DW, Dellinger EP, Olsen KM. Balancing the risks and benefits of surgical prophylaxis timing and duration do matter. Am J Heal Pharm 2013;70:195-283.
41 Branch-Elliman W, O'Brien W, Strymish J, et al. Association of duration and type of surgical prophylaxis with AntimicrobialAssociated adverse events. JAMA Surg 2019;154:590-8.

42 Pinto-Lopes R, Sousa-Pinto B, Azevedo LF. Single dose versus multiple dose of antibiotic prophylaxis in caesarean section: a systematic review and meta-analysis. BJOG 2017;124:595-605.

43 Slobogean GP, Kennedy SA, Davidson D, et al. Single- versus multiple-dose antibiotic prophylaxis in the surgical treatment of closed fractures: a meta-analysis. J Orthop Trauma 2008;22:264-9.

44 lerano C, Nankervis J-AM, James R, et al. Surgical antimicrobial prophylaxis. Aust Prescr 2017;40:225-9.

45 Bratzler DW, Dellinger EP, Olsen KM, et al. Clinical practice guidelines for antimicrobial prophylaxis in surgery. Surg Infect 2013;14:73-156. 